\title{
PENGARUH IMPLEMENTASI LAYANAN BIMBINGAN PRIBADI SOSIAL TERHADAP PENYESUAIAN DIRI ANAK BERKEBUTUHAN KHUSUS (ABK) DI SEKOLAH INKLUSIF SMAN 10 SURABAYA
}

\author{
Ana Rafikayati ${ }^{1}$, Lutfi Isni Badiah ${ }^{2}$, dan Boy Soedarmadji ${ }^{3}$ \\ Universitas PGRI Adi Buana Surabaya \\ $\underline{\text { ana.rafikayati@gmail.com}}^{1}$. $\underline{\text { lutfi@unipasby.ac.id }}^{2}$ dan $\underline{\text { boy@unipasby.ac.id }}^{3}$
}

\begin{abstract}
ABSTRAK
Pada umumnya, Anak Berkebutuhan Khusus (ABK) bersekolah di Sekolah Luar Biasa (SLB) yang memiliki karaktersistik homogen (satu jenis kekususan) misalnya SLBA untuk anak tunanetra, SLB-B untuk anak tunarungu, dll. Dengan mulai dikembangkan pendidikan inklusif, kini ABK dapat belajar bersama-sama dengan anak reguler di sekolah umum. ABK yang dulunya bersekolah di lingkungan homogen kini harus menyesuaikan diri dengan lingkungan yang heterogen ini. Banyak ABK yang mengalami kesulitan ini sehingga mereka sulit bersosialisasi dengan lingkungan. Dampaknya ABK cenderung menarik diri dari lingkungan. Berdasarkan paparan tersebut, diperlukan program khusus agar ABK dapat menyesuaikan diri dengan lingkungannya salah satunya melalui layanan bimbingan pribadi sosial. Tujuan dari penelitian ini adalah untuk mengetahui pengaruh implementasi layanan bimbingan pribadi sosial terhadap penyesuaian diri ABK di sekolah inklusif SMAN 10 Surabaya. Penelitian ini menggunakan pendekatan kuantitatif dengan jenis penelitian ekperimen (TrueExperimental Design). Hasil penelitian menunjukkan bahwa nilai $\mathrm{Z}$ hitung $=-3.062$ dengan $P=0.002$ dengan taraf signifikansi $(\alpha) 5 \%$. Hasil tersebut lebih kecil dari 0,005, sehingga hipotesis penelitian terbukti kebenaranya. Dengan demikian dapat disimpulkan bahwa layanan bimbingan pribadi sosial berpengaruh terhadap penyesuaian diri ABK di SMAN 10 Surabaya.
\end{abstract}

Keywords: Layanan Bimbingan Pribadi Sosial, Penyesuaian Diri ABK.

\section{PENDAHULUAN}

Anak Berkebutuhan Khusus atau ABK merupakan individu dengan karakteristik khusus yang berbeda dengan anak pada umumnya, khususnya pada aspek kognitif, emosi, atau fisik. Adapun jenis ABK diantaranya (1) anak tunanetra; (2) anak tunarungu; (3) anak tunagrahita; (4) anak tunadaksa; (5) anak autis; (6) anak ADD/ADHD; (7) anak berkesulitan belajar; dan (8) anak slow learner. Setiap jenis kekhususan tersebut memiliki karaktersitik masing-masing.

Pada umumnya, ABK bersekolah di Sekolah Luar Biasa (SLB) yang memiliki karaktersistik homogen (satu jenis kekususan), misalnya SLB-A adalah sekolah khusus untuk anak tunanetra, SLB-B untuk anak tunarungu, SLB-C untuk anak tunagrahita, dll. Dengan mulai dikembangkan pendidikan 
inklusif, kini ABK memiliki hak sama dalam memperoleh pendidikan seperti halnya anak-anak pada umumnya. Kini mereka dapat belajar bersama-sama dengan anak reguler di sekolah umum (sekolah inklusif).

Pendidikan inklusif adalah sistem penyelenggaraan pendidikan yang memberikan kesempatan kepada semua peserta didik yang memiliki kelainan dan memiliki potensi kecerdasan dan/atau bakat istimewa untuk mengikuti pendidikan atau pembelajaran dalam lingkungan pendidikan di sekolah reguler bersamasama dengan peserta didik regular, mulai dari jenjang pendidikan usia dini (PAUD) hingga jenjang SMA atau SMK. Pendidikan inklusif di Indonesia mulai dikembangkan sebagai dampak dari isuisu dunia tentang pendidikan untuk semua. Pendidikan inklusif inklusif adalah sebuah sistem pendidikan yang ditengarai lebih ramah dan tidak diskriminatif terhadap mereka (Direktorat PPK-LK Kemendikbud, 2011:8).

Masuknya ABK di sekolah inklusif ternyata membawa permasalahan tersendiri. ABK yang dulunya bersekolah di lingkungan homogen, kini harus menyesuaikan diri dengan lingkungan yang heterogen dengan berbagai jenis karakteristik anak reguler. Banyak ABK yang mengalami kesulitan ini sehingga mereka sulit bersosialisasi dengan lingkungan dan cenderung menyendiri. Hal ini sesuai dengan pendapat Santrock (2003) yang menyatakan bahwa pada umumnya, ABK mengalami kesulitan dalam menyesuaikan diri dengan sekolah dan teman sebayanya dikarenakan mereka sangat peka terhadap keterbatasan yang dimilikinya.

Salah satu penyebab sulitnya ABK melakukan penyesuaian diri dengan dilingkungannya adalah karena keterbatasan yang dimilikinya. Baughan (2012) memaparkan bahwa salah satu penyebab ABK sulit melakukan penyesuaian diri adalah karena adanya hambatan dalam kemampuan sosial dan komunikasi serta hambatan dalam perilaku dan kemampuan akademis mereka. Selain faktor internal dari siswa ABK, salah satu penyebab lainnya adalah karena kurangnya penerimaan positif dari warga sekolah dalam hal ini teman sebaya dan guru terhadap kehadiran ABK.

Berdasarkan observasi yang dilakukan di SMAN 10 Surabaya, salah satu sekolah inklusif di Kota Surabaya pada tanggal 4, 13, dan 25 April 2016 diperoleh data bahwa terdapat 14 siswa yang memiliki masalah dalam menyesuaikan diri. 14 siswa tersebut terdiri dari 3 siswa tunanetra, 1 tunarungu, 3 tunadaksa, 1 autis, dan 6 lamban belajar. Dari observasi yang dilakukan, diketahui bahwa beberapa siswa siswa mengalami kesulitan dalam bersosialisasi (membangun relasi) 
dengan teman sebaya khususnya ketika pembelajaran. Hal tersebut berdampak pada prestasi akademik mereka karena pada jenjang SMA banyak pembelajaran yang menuntut siswa untuk bekerja sama dalam kelompok.

Penyesuaian diri yang rendah akan menyebabkan kesulitan-kesulitan bagi anak dalam bersosialisasi di sekolah. Hurlock (1980:239) menyatakan bahwa dampak dari gagalnya penyesuaian diri diantaranya terbentunya (1) sikap tidak bertanggung jawab; (2) sikap agresif; (3) perasaan khawatir tanpa sebab; (4) cemas ketika jauh dari tempat yang dikenal; (5) perasaan mudah menyerah; (6) sering berkhayal; (7) Mundur ke tingkat perilaku yang sebelumnya agar disenangi dan diperhatikan teman; (8) Menggunakan mekanisme pertahanan ego. Lebih jauh lagi jika penyesuaian diri siswa tidak segera diatasi, dampaknya siswa akan kesulitan dalam menyelesaikan berbagai permasalahan hidup, baik dalam kehidupan berkeluarga, sekolah, dan masyarakat.

\section{Mengingat} pentingnya kemampuan penyesuain diri, maka diperlukan langkah upaya pemecahan masalah penyesuain diri bagi ABK. Salah satu solusi yang dapat diberikan adalah melalui layanan bimbingan pribadi sosial. Layanan bimbingan pribadi sosial adalah bantuan yang diberikan kepada individu untuk menyelesaikan masalah sosial pribadi yang dialaminya seperti masalah hubungan sosial, permasalahan sifat dan kemampuan diri, penyesuaian diri dengan lingkungan pendidikan dan masyarakat. Serta dapat menyelesaiakan konflik (Yusuf, 2006:11).

Layanan bimbingan pribadi sosial merupakan langkah efektif meningkatkan kemampuan penyesuaian diri anak karena layanan bimbingan pribadi sosial fokus pada optimalisasi kemampuan diri anak serta peningkatan kemampuan dalam melakukan hubungan sosial. Hal ini sesuai dengan hasil penelitian Wijaya dan Kusbandiami (2011) yang menyatakan bahwa terdapat hubungan positif antara implementasi layanan bimbingan pribadi sosial dengan penyesuaian diri siswa Kelas VII SMP Negeri 32 Surabaya.

Keefektifan bimbingan pribadi sosial juga diperkuat dengan hasil penelitian Nurfuad (2013) yang menyatakan bahwa bimbingan pribadi sosial dalam setting bimbingan kelompok efektif dalam meningkatkan penyesuaian diri siswa kelas VIII B di SMPN 2 Juwana. Lebih lanjut lagi, selain meningkatkan penyesuaian diri anak, layanan bimbingan pribadi sosial juga akan meningkatkan kepercayaan diri siswa. Kepercayaan diri dipelukan sebagai modal dalam menjalin hubungan sosial. Tohir (2015) menyatakan bahwa bimbingan pribadi 
sosial dapat meningkatkan kepercayaan diri siswa.

Layanan bimbingan pribadi sosial awalnya dikembangkan untuk anak regular (non ABK). Meskipun begitu, dengan mulai berkembangnya pendidikan inklusif dan variasi penanganan bagi ABK, layanan bimbingan pribadi sosial juga mulai dikembangkan untuk ABK. Riyanto (2014) memaparkan bahwa layanan bimbingan pribadi sosial mulai diimplementasikan pada anak tunanetra dan hasilnya layanan bimbingan pribadi sosial efektif dalam meningkatkan kepercayaan diri siswa tunanetra di MTs Yayasan Kesejahteraan Tunanetra Islam (Yaketunis) Yogyakarta.

Berdasarkan paparan tersebut, maka peneliti mengambil "pengaruh implementasi layanan bimbingan pribadi sosial terhadap penyesuaian diri ABK di sekolah inklusif SMAN 10 Surabaya" sebagai judul penelitian. Dengan layanan bimbingan pribadi sosial ini diharapkan ABK dapat melakukan penyesuaian diri yang baik dengan lingkungannya sehingga mereka dapat berkembang secara optimal baik secara akademik maupun non-akademik di sekolah inklusif.

\section{TUJUAN PENELITIAN}

Tujuan penelitian dalam penelitian ini adalah "untuk mengetahui pengaruh implementasi layanan bimbingan pribadi sosial terhadap penyesuaian diri ABK di sekolah inklusif SMAN 10 Surabaya".

\section{METODE}

Penelitian ini menggunakan pendekatan kuantitatif dengan jenis penelitian Pra-Eksperimental. Adapun rancangan penelitian yang digunakan dalam penelitian ini adalah One-Group Pretest-Posttest Designs. Lebih lanjut rancangan penelitian ini selengkapnya dapat dilihat pada Gambar 1 sebagai berikut.

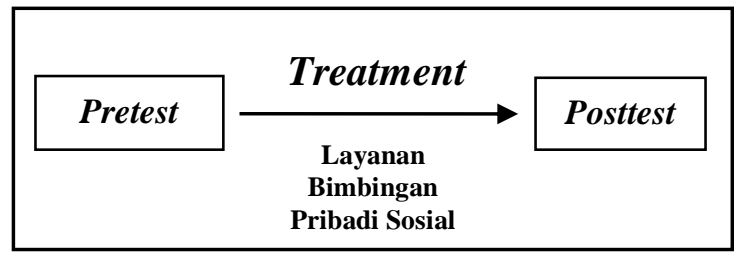

Gambar 1

Rancangan Penelitian

Keterangan:

$\mathrm{T}_{1}$ : Pretest (pengukuran penyesuaian diri siswa sebelum diberikan treatment).

$\mathrm{T}_{2}$ : Posttest (pengukuran penyesuaian diri siswa setelah diberikan treatment).

$X$ : Treatment atau perlakuan berupa implementasi layanan bimbingan pribadi sosial. Treatment diberikan selama 4 kali pertemuan dengan durasi masing-masing pertemuan 2 x 45 menit.

Subyek penelitian dalam penelitian ini adalah 12 siswa ABK di SMAN 10 Surabaya yang mengalami kesulitan dalam menyesuaikan diri. Teknik pengumpulan data dalam penelitian ini 
menggunakan teknik pengamatan atau observasi, dan angket. Sedangkan teknik analisis data yang digunakan adalah dengan teknik uji peringkat bertanda Wilcoxon (Wilcoxon Signed Ranks Test).

\section{HASIL DAN PEMBAHASAN}

Pre-test diberikan diawal sebelum intervensi. Selanjutnya subyek penelitian diberikan intervensi berupa pemberian berupa implementasi layanan bimbingan pribadi sosial. Treatment diberikan selama 4 kali pertemuan dengan durasi masing-masing pertemuan 2 x 45 menit. Setalah dilakukan intervensi, selanjutnya dilakukan post-test untuk mengukur pengaruh layanan bimbingan pribadi sosial. Adapun hasil Pre-test dan post-test dalam penelitian ini dapat dilihat di Tabel 1 sebagai berikut.

\section{Tabel 1}

Hasil Pre-test dan Post-test

\begin{tabular}{|c|c|c|}
\hline Subyek & Hasil Pre-Test & Hasil Post-Test \\
\hline AG & 60 & 87 \\
\hline RS & 48 & 90 \\
\hline SN & 56 & 85 \\
\hline DN & 58 & 89 \\
\hline DY & 51 & 99 \\
\hline RM & 42 & 78 \\
\hline AS & 40 & 88 \\
\hline FR & 49 & 100 \\
\hline FK & 65 & 105 \\
\hline MH & 76 & 98 \\
\hline RO & 80 & 110 \\
\hline YN & 81 & 110 \\
\hline Mean & 58,83333333 & 94,91666667 \\
\hline
\end{tabular}

Data tersebut selanjutnya dianalisis dengan uji peringkat bertanda Wilcoxon (Wilcoxon Signed Ranks Test) dengan SPSS 21. Berdasarkan analisis data diketahui bahwa nilai $\mathrm{Z}$ hitung = 3.062 dengan $\mathrm{P}=0.002$ dengan taraf signifikansi $(\alpha)$ ) 5\%. Hasil tersebut lebih kecil dari 0,005, sehingga hipotesis penelitian terbukti kebenaranya. Dengan demikian dapat disimpulkan bahwa layanan bimbingan pribadi sosial berpengaruh terhadap penyesuaian diri ABK di SMAN 10 Surabaya.

Bimbingan konseling pribadi sosial merupakan suatu bimbingan atau bantuan untuk membantu para individu memecahkan masalah-masalah pribadi dan sosial seperti hubungan dengan sesama, penyesuaian diri dengan lingkungan pendidikan dan masyarakat sekitarnya, dan penyelesaian konflik (Yusuf dan Nurihsan, 2009).

$$
\text { Sedangkan Prayitno }
$$

mengemukakan: Bimbingan pribadi sosial adalah bantuan yang diberikan kepada seseorang (individu) atau sekelompok orang agar mereka itu dapat berkembang menjadi pribadi-pribadi yang mandiri.Kemandirian ini mencakup 5 fungsi pokok yang hendaknya dijalankan oleh pribadi yang mandiri yaitu: (1) mengenal diri sendiri dan lingkungan; (2) menerima diri sendiri dan lingkungan secara positif dan dinamis; (3) mengambil keputusan; (4) mengarahkan diri; (5) mewujudkan diri.

Tujuan dari bimbingan pribadisosial adalah untuk membantu siswa agar: a) memiliki kesadaran diri, yaitu menggambarkan penampilan dan 
mengenal kekhususan yang ada pada dirinya, b) dapat mengembangkan sikap positif, seperti menggambarkan orangorang yang mereka senangi, c) membuat pilihan secara sehat, d) mampu menghargai orang lain, e) memiliki rasa tanggung jawab, f) mengembangkan ketrampilan hubungan antarpribadi, g) dapat menyelesaikan konflik, h) dapat membuat keputusan secara efektif (Sukardi, 2008).

Layanan bimbingan pribadi sosial merupakan langkah efektif meningkatkan kemampuan penyesuaian diri anak karena layanan bimbingan pribadi sosial fokus pada optimalisasi kemampuan diri anak serta peningkatan kemampuan dalam melakukan hubungan sosial. Hal ini sesuai dengan hasil penelitian Wijaya dan Kusbandiami (2011) yang menyatakan bahwa terdapat hubungan positif antara implementasi layanan bimbingan pribadi sosial dengan penyesuaian diri siswa Kelas VII SMP Negeri 32 Surabaya.

Keefektifan bimbingan pribadi sosial juga diperkuat dengan hasil penelitian Nurfuad (2013) yang menyatakan bahwa bimbingan pribadi sosial dalam setting bimbingan kelompok efektif dalam meningkatkan penyesuaian diri siswa kelas VIII B di SMPN 2 Juwana. Lebih lanjut lagi, selain meningkatkan penyesuaian diri anak, layanan bimbingan pribadi sosial juga akan meningkatkan kepercayaan diri siswa. Kepercayaan diri dipelukan sebagai modal dalam menjalin hubungan sosial. Tohir (2015) menyatakan bahwa bimbingan pribadi sosial dapat meningkatkan kepercayaan diri siswa.

Layanan bimbingan pribadi sosial awalnya dikembangkan untuk anak regular (non ABK). Meskipun begitu, dengan mulai berkembangnya pendidikan inklusif dan variasi penanganan bagi ABK, layanan bimbingan pribadi sosial juga mulai dikembangkan untuk ABK. Riyanto (2014) memaparkan bahwa layanan bimbingan pribadi sosial mulai diimplementasikan pada anak tunanetra dan hasilnya layanan bimbingan pribadi sosial efektif dalam meningkatkan kepercayaan diri siswa tunanetra di MTs Yayasan Kesejahteraan Tunanetra Islam (Yaketunis) Yogyakarta.

Hasil yang serupa ditemukan pada penelitian ini yakni pada siswa ABK di SMAN 10 Surabaya ditemukan data bahwa layanan bimbingan pribadi sosial berpengaruh terhadap penyesuaian diri $A B K$ di SMAN 10 Surabaya.

Berdasarkan paparan tersebut, dapat disimpulkan bahwa dengan penerapan layanan bimbingan pribadi sosial, kemampuan penyesuaian diri ABK di sekolah inklusif meningkat. Hal tersebut dapat membantu anak dalam bersosialisasi di lingkungan sekolah inklusif yang bersifat heterogen 
sehingga dapat membantu ABK dalam proses belajar sehingga mereka dapat mencapai prestasi secara optimal.

\section{SIMPULAN}

Hasil analisis data menunjukkan bahwa bahwa nilai $\mathrm{Z}$ hitung $=-3.062$ dengan $\mathrm{P}=0.002$ dengan taraf signifikansi $(\alpha)$ ) 5\%. Hasil tersebut lebih kecil dari 0,005, sehingga hipotesis penelitian terbukti kebenaranya. Dengan demikian dapat disimpulkan bahwa layanan bimbingan pribadi sosial berpengaruh terhadap penyesuaian diri ABK di SMAN 10 Surabaya.

\section{SARAN}

Perlu dilakukan penelitian lanjutan tentang aspek nonakademik siswa ABK lainnya sehingga ABK dapat belajar dengan optimal di sekolah inklusif.

\section{DAFTAR PUSTAKA}

Baughan, C.C. (2012). An examination of predictive factors related to school adjustment for children with disabilities transitioning into formal school setting. (Disertasi). Clemson University, South Carolina.

Direktorat PPK-LK Kemendikbud. (2011). Pedoman Umum Penyelenggaraan Pendidikan Inklusif (Sesuai Permendiknas No 70 Tahun 2009). Jakarta: Kemendikbud.

Nurfuad. (2013). Meningkatkan penyesuaian diri terhadap lingkungan sekolah melalui layanan bimbingan kelompok pada siswa kelas VIII B SMPN 2
Juwana Tahun 2012/2013. Skripsi. BK FIP UNNES.

Nurihsan, Achmad Juntika. (2006). Bimbingan dan Konseling "Dalam Berbagai Latar dan Kehidupan". Bandung: Rineka Cipta.

Prayitno. (2001). Panduan Kegiatan Pengawasan Bimbingan Dan Konseling Di Sekolah. Jakarta: PT Rineka Cipta.

Riyanto, M.A. (2014). Implementasi layanan bimbingan pribadi-sosial terhadap siswa tunanetra MTs Yaketunis (Yayasan Kesejahteraan Tunanetra Islam) Yogyakarta. Skripsi. BK FDK UIN Sunan Kalijaga Yogyakarta.

Santrock, John W. Adolescence. Perkembangan Remaja. Edisi Keenam. Jakarta: Erlangga, 2003.

Sukardi, Dewa Ketut. (2008). Pengantar Pelaksanaan Program Bimbingan dan Konseling di Sekolah. Jakarta: Rineka Cipta.

Tohir, Dani. (2015). Program bimbingan pribadi sosial untuk peningkatan kepercayaan diri siswa. Universitas Pendidikan Indonesia (repository.upi.edu).

Wijaya dan Kusbandiami. (2011). Hubungan antara layanan bimbingan sosial dengan penyesuaian diri siswa kelas $X$ Akuntansi SMK Pemuda Krian. Jurnal Helper BK FKIP UNIPA Surabaya Vol. 22 No.2 September 2011.

Yusuf, Syamsu. (2006). Program Bimbingan dan Konselingsi di Sekolah (SLTP dan SLTA). Bandung: Pustaka Bani Quraisy. 